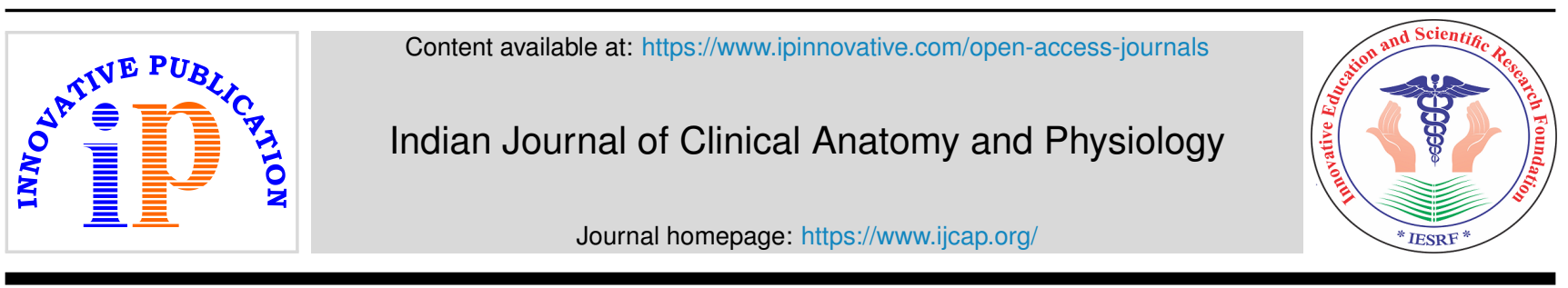

Original Research Article

\title{
Study on branching pattern of segmental branches of splenic artery in human cadaveric spleens by dissection method
}

\author{
Shwetha $\mathbf{K}^{1}$,*, Dakshayani $\mathbf{K}^{1}$ \\ ${ }^{1}$ Dept. of Anatomy, Mysore Medical College and Research Institute, Mysore, Karnataka, India
}

\section{A R T I C L E I N F O}

\section{Article history:}

Received 16-02-2021

Accepted 23-02-2021

Available online 12-04-2021

Keywords:

Splenic artery

Segmental branches

Anastomosis

Partial splenectomy

\begin{abstract}
A B S T R A C T
Introduction: Spleen is the largest lymphoid organ. It is supplied by splenic artery the largest branch of coeliac trunk. It traverses through the lienorenal ligament to reach near the hilum of the spleen, where it divides into two or three primary branches, each of which is subdivided mostly into two or four secondary branches. Moreover, a superior polar arteries and inferior polar arteries are given from splenic trunk or from one of its primary branches, which goes to the poles of the spleen, without entering the hilum. It can be named as superior and inferior polar artery. The human spleen is divided accordingly into two or three main segments. The segments of spleen are separated by a definite avascular plane. Hence the partial removal of the spleen is possible, as the spleen is divided into segments, separated by fibrous septa and each segment is supplied by its own main artery. The present study was undertaken to study in detail the segmental branches of splenic artery which divide the spleen into various segments, its pattern of distribution and also to find out any inter-segmental arterial anastomosis by dissection method.

Objectives: 1 . To study segmental branches of splenic artery. 2 . To study the anastomosis between the segmental branches. 3 . To study the branching pattern of terminal division of splenic artery.

Materials and Methods: The present study was conducted on 79 adult human cadaver spleens by dissection method, irrespective of their age and sex, fixed in $10 \%$ formalin solution, collected from the Department of Anatomy and Forensic Medicine, Mysore Medical College and Research Institute, Mysore. Results: 1 . Two primary segmental branches were seen in 56 (70.9\%) specimens, three primary segmental branches were seen in $19(24.1 \%)$ specimens and four primary segmental branches were seen in $4(5.1 \%)$ specimens. 2. Superior polar artery was present in $18(22.8 \%)$ specimens and inferior polar artery was present in $32(40.5 \%)$ and both superior and inferior polar artery was seen in $5(6.3 \%)$ specimens. 3. Anastomosis between the primary segmental branches were seen in 11(13.9\%) specimens. 4 . The distributive type of branching pattern of terminal division of splenic artery was present in $50(63.3 \%)$ specimens, and the marginal type of branching pattern was present in 29 (36.7\%) specimens.

Conclusion: The present study adds up to the existing knowledge regarding the segmental branches of splenic artery, the better anatomical knowledge about segmental distribution of splenic artery and its variations are important for the partial removal of the spleen.
\end{abstract}

(C) This is an open access article distributed under the terms of the Creative Commons Attribution License (https://creativecommons.org/licenses/by/4.0/) which permits unrestricted use, distribution, and reproduction in any medium, provided the original author and source are credited.

\section{Introduction}

The spleen is a highly vascular and friable organ. It is the largest secondary lymphoid organ, which contains $25 \%$ of the body lymphoid tissue and has both haematological and immunological functions. Spleen is supplied by splenic

\footnotetext{
* Corresponding author.

E-mail address: shwethajagannath85@gmail.com (Shwetha K).
}

artery which is the largest branch of coeliac trunk. ${ }^{1}$ It traverses through the lienorenal ligament to reach near the hilum of the spleen, where it divides into two or three primary branches, each of which is subdivided mostly into two or four secondary branches. Moreover, a superior polar arteries and inferior polar arteries are given from splenic trunk or from one of its primary branches, which goes to the poles of the spleen, without entering the hilum. It is called 
as superior and inferior polar branches. The human spleen is divided accordingly into two or three main segments. Each main segment is also divided usually into two to four less constant secondary segments. The segments of spleen are separated by a definite avascular plane.

The partial removal of the spleen is possible, as the spleen is divided into segments, separated by fibrous septa and each segment is supplied by its own main artery. ${ }^{2}$ The presence of splenic segmentation could be attributed to its development or to the terminal division of the artery.

Better anatomical knowledge about segmental distribution of splenic artery and its variations are important for the partial removal of the organ. So, keeping the applied aspect and clinical significance of segmental branches of splenic artery and to add more knowledge to the existing one, the present study was undertaken to study the segmental branches of splenic artery which divide the spleen into various segments, its pattern of distribution and also to find out any inter-segmental arterial anastomosis by dissection method.

\section{Aims and Objectives}

To study the branching pattern of the segmental branches of splenic artery and to find out if there is any the anastomosis between the segmental branches.

\section{Materials and Methods}

The present study is conducted on 79 Human cadaver spleens, irrespective of their age and sex, fixed in $10 \%$ formalin solution, collected from the department of Anatomy and Forensic Medicine, Mysore Medical College and Research Institute.

The gross dissection was done by following the guide lines of Cunningham's Manual. The spleen was identified and freed from the posterior abdominal wall and stomach by cutting through the gastrosplenic and lienorenal ligaments. The splenic artery was cut about $10 \mathrm{~cm}$ proximal to hilum of spleen, then the spleen was removed. The fascia and fat was cleared at the hilum to expose the segmental branches of the splenic artery. Firstly, the primary segmental branches of the splenic artery and its branching patterns were identified and noted, then by removing the parenchyma along the primary branches by piecemeal dissection the secondary branches and also inter segmental arterial anastomosis if any were noted.

\section{Results}

Two primary segmental branches were seen in $56(70.9 \%)$ specimens, three primary segmental branches were seen in $19(24.1 \%)$ specimens and four primary segmental branches were seen in $4(5.1 \%)$ specimens.

Superior polar artery was present in 18 (22.8\%) specimens and inferior polar artery was present in 32
(40.5\%) specimens and both superior and inferior polar artery was seen in $5(6.3 \%)$ specimens.

Superior polar artery arising from main trunk was present in $12(67 \%)$ specimens and superior polar artery arising from primary branch seen in $6(33 \%)$ specimens.

Inferior polar artery was seen arising from main trunk in $15(47 \%)$ specimens, from left gastroepiploic artery in $9(28 \%)$ specimens and from primary branch in $8(25 \%)$ specimens.

Anastomosis between the primary segmental branches were seen in $11(13.9 \%)$ specimens.

The extra-parenchymal anastomosis of primary segmental branches was seen in $5(6.3 \%)$ specimens. The intra-parenchymal anastomosis was seen in $3(3.7 \%)$ and sub-capsular type of anastomosis was seen in $3(3.7 \%)$ specimens.

The distributive type of branching pattern was present in $50(63.3 \%)$ specimens. The marginal type of branching pattern was present in $29(36.7 \%)$ specimens.

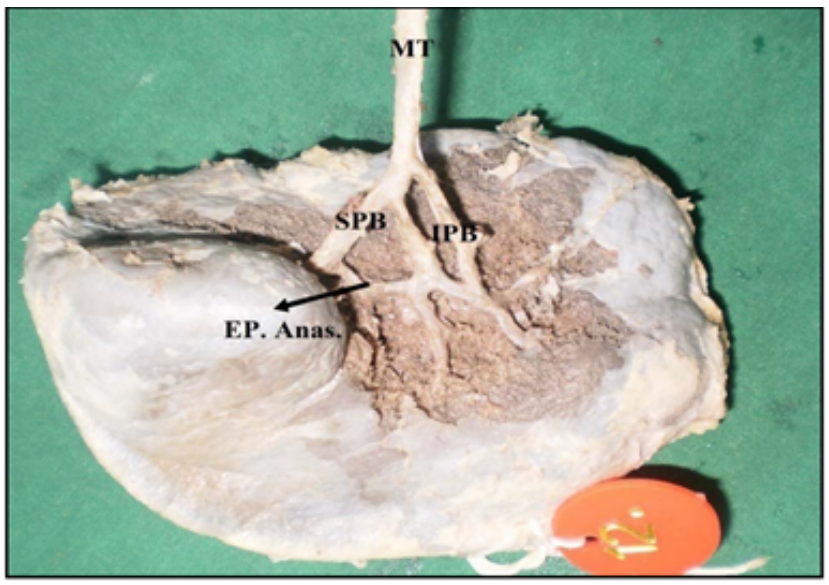

Fig. 1: Extra-parenchymal anastomosis between superior and inferior primary branches

(MT- Main Trunk, SPB - Superior Primary Branch, IPB -Inferior Primary Branch, EP. Anas. - Extra Parenchymal Anastomosis)

Table 1: Number of primary segmental branches of splenic artery

\begin{tabular}{lccc}
\hline S. & Primary & Number of \\
No. & $\begin{array}{c}\text { segmental } \\
\text { branches }\end{array}$ & $\begin{array}{c}\text { Percentage } \\
(\%)\end{array}$ \\
1 & One & Nil & 0 \\
2 & Two & 56 & 70.9 \\
3 & Three & 19 & 24.1 \\
4 & Four & 4 & 5.1 \\
5 & Total & 79 & 100 \\
\hline
\end{tabular}

\section{Discussion}

Spleen is supplied by splenic artery, which terminates at the hilum by dividing into 2 or 3 terminal branches. 
Table 2: Types of anastomosis

\begin{tabular}{lcc}
\hline Types of anastomosis & Number of specimen & Percentage $(\%)$ \\
None & 68 & 86.3 \\
Extra-parenchymal & 5 & 6.3 \\
Intra-parenchymal & 3 & 3.7 \\
Sub-capsular & 3 & 3.7 \\
Total & 79 & 100.0 \\
\hline
\end{tabular}

Table 3: Comparison of number of primary segmental branches of splenic artery with the previous studies

\begin{tabular}{|c|c|c|c|c|}
\hline \multirow{2}{*}{ Author } & \multirow{2}{*}{$\begin{array}{c}\text { Number of specimens } \\
\text { studied }\end{array}$} & \multicolumn{3}{|c|}{ Number of primary segmental branches } \\
\hline & & 2 & 3 & 4 \\
\hline Gupta CD et al. (1976) ${ }^{3}$ & 50 & $84 \%$ & $16 \%$ & - \\
\hline Mikhail Y et al. (1979) ${ }^{4}$ & 25 & $77 \%$ & $23 \%$ & - \\
\hline Katrisis E et al. $(1982)^{5}$ & 70 & $88.7 \%$ & $14.3 \%$ & - \\
\hline Mandarin LCA $(1983)^{6}[6]$ & 25 & $68.2 \%$ & $10.6 \%$ & $4.5 \%$ \\
\hline Garcia PJA $(1988)^{7}$ & 181 & $92.82 \%$ & $7.18 \%$ & - \\
\hline Sow ML $(1991)^{8}$ & 32 & $84 \%$ & $16 \%$ & - \\
\hline Silva LFA $(2010)^{9}$ & - & $93.34 \%$ & $6.66 \%$ & - \\
\hline Chaware PN et al. (2012) ${ }^{10}$ & - & $85.58 \%$ & $14.42 \%$ & - \\
\hline Swamy VL et al. (2013) ${ }^{11}$ & 60 & $66 \%$ & $17 \%$ & $17 \%$ \\
\hline Londhe SR et al. (2013) ${ }^{12}$ & 50 & $90 \%$ & $10 \%$ & - \\
\hline Present study & 79 & $70.9 \%$ & $24.1 \%$ & $5.1 \%$ \\
\hline
\end{tabular}

Table 4: Comparison of polar arteries with the previous studies

\begin{tabular}{|c|c|c|c|}
\hline \multirow{2}{*}{ Author } & \multicolumn{3}{|c|}{ Polar artery } \\
\hline & Superior & Inferior & Both \\
\hline Present Study & $22.8 \%$ & $40.5 \%$ & $6.3 \%$ \\
\hline Mikhail Y et al ${ }^{4}$ & $18 \%$ & $50 \%$ & $12 \%$ \\
\hline Garcia PA et al ${ }^{7}$ & $29.28 \%$ & $44.75 \%$ & $10.49 \%$ \\
\hline Chaware PN et al ${ }^{10}$ & $28.82 \%$ & $42.34 \%$ & $11.7 \%$ \\
\hline Swamy VL et al ${ }^{11}$ & $41.6 \%$ & $25 \%$ & $16.6 \%$ \\
\hline Londhe SR et al ${ }^{12}$ & $32 \%$ & $56 \%$ & $24 \%$ \\
\hline
\end{tabular}

Table 5: The comparison of anastomosis between segmental branches with the previous studies

\begin{tabular}{|c|c|}
\hline Author & Observation \\
\hline Present study & $13.9 \%$ \\
\hline Gupta CD et $\mathrm{al}^{3}$ & No anastomosis \\
\hline Garcia PJA et al $^{7}$ & $19.89 \%$ \\
\hline Mandarim LCA et al ${ }^{6}$ & $16.7 \%$ \\
\hline Chaware PN et al ${ }^{10}$ & $1.80 \%$ \\
\hline
\end{tabular}

Table 6: Comparison of types of anastomosis with the previous studies

\begin{tabular}{lccc}
\hline Author & Extra-parenchymal & $\begin{array}{c}\text { Type of anastomosis } \\
\text { Intra-parenchyma }\end{array}$ & Sub-capsular \\
Present study & $6.3 \%$ & $3.7 \%$ & $3.7 \%$ \\
Sow ML et al. ${ }^{8}$ & $9 \%$ & $32 \%$ & - \\
Holibkova A et al. ${ }^{13}$ & $15 \%$ & $45 \%$ & $8 \%$ \\
\hline
\end{tabular}

Table 7: The comparison of branching pattern with the previous studies

$\begin{array}{lcc}\text { Author } & \text { Branching Pattern } & \text { Marginal type } \\ \text { Present study } & \text { Distributive type } & 36.7 \% \\ \text { Michels NA et al. }{ }^{14} & 63.3 \% & 30 \% \\ \text { Holibkova A et al. }{ }^{13} & 70 \% & 20 \% \\ \text { Charles Brunicardi F et al. }{ }^{15} & 80 \% & 30 \%\end{array}$




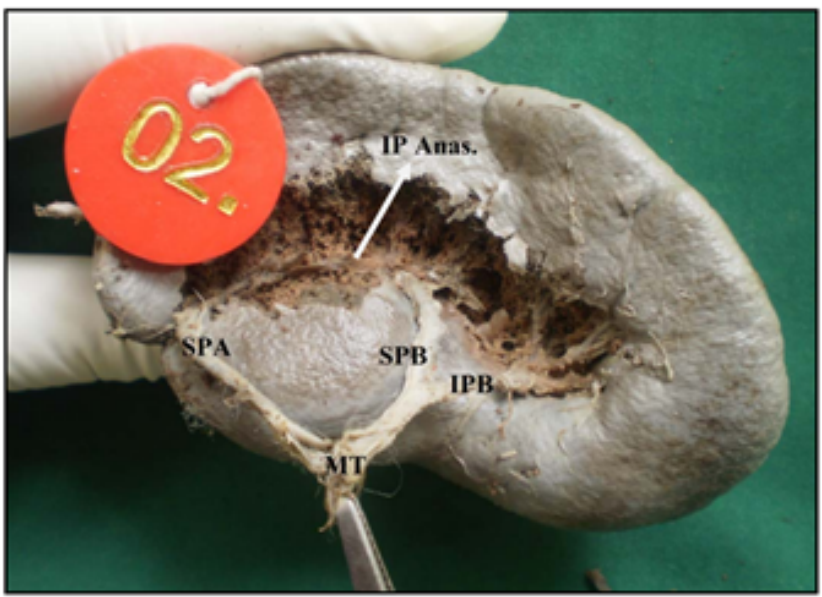

Fig. 2: Intra-parenchymal anastomosis between superior primary branch and superior polar artery

(MT - Main Trunk, SPB - Superior Primary Branch, IPB - Inferior Primary Branch, SPA - Superior Polar Artery, IP. Anas. - Intra Parenchymal Anastomosis)

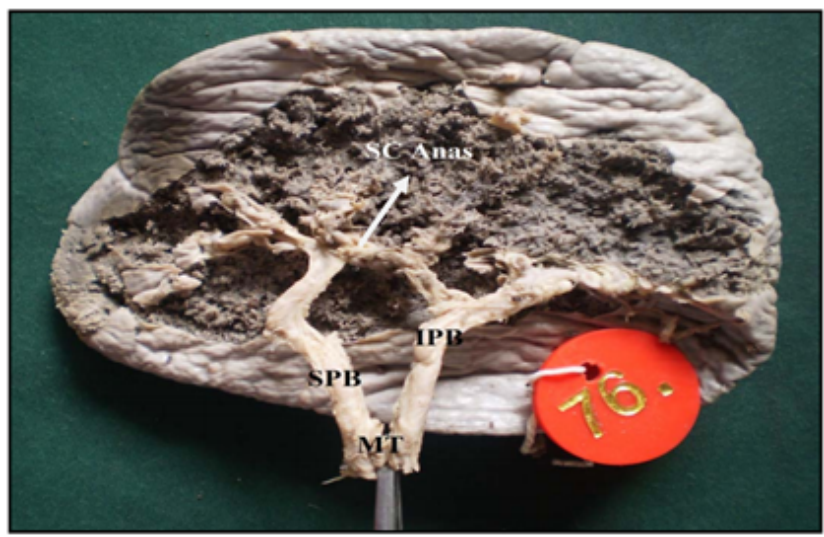

Fig. 3: Sub-capsular type of anastomosis between superior and inferior primary branches

(MT - Main Trunk, SPB - Superior Primary Branch, IPB - Inferior Primary Branch, SC. Anas. - Sub capsular Anastomosis)

These are named as superior, middle and inferior primary branches. These branches supply a particular part of the spleen which is separated by an avascular plane. Thus, these branches divide the spleen into definite arterial segments. So these arteries can be considered as the primary segmental branches. ${ }^{5}$ In the present study two primary branches were seen in $56(70.9 \%)$ specimens, three in $19(24.1 \%)$ specimens and four in $4(5.1 \%)$ specimens. Other studies showed only 2 to 3 primary branches. In this study we have observed 2 to 4 primary branches. The comparison of number of primary branches with the previous studies is given in Table 3.

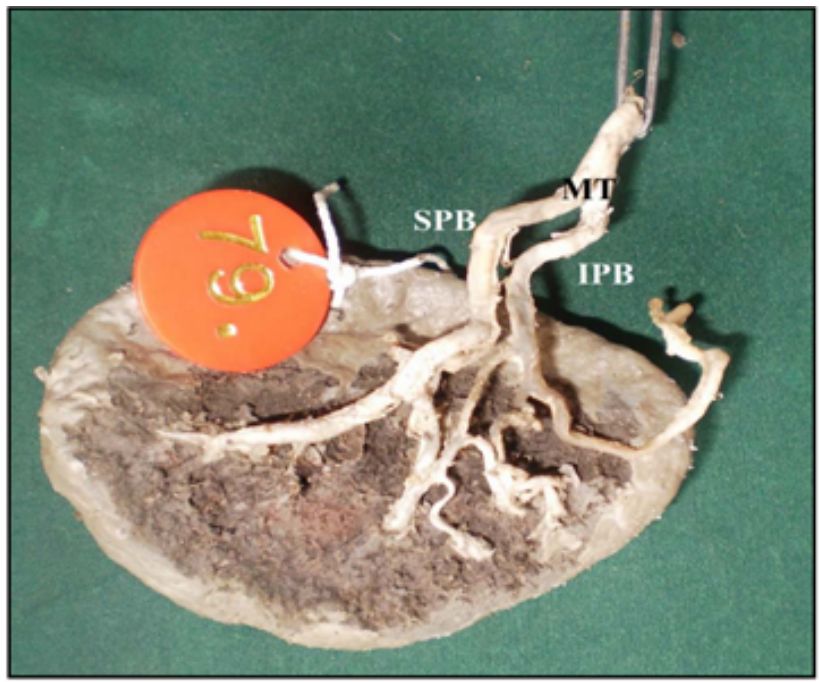

Fig. 4: Distributive type of branching pattern (MT - Main Trunk, SPB- Superior Primary Branch, IPB - Inferior Primary Branch)

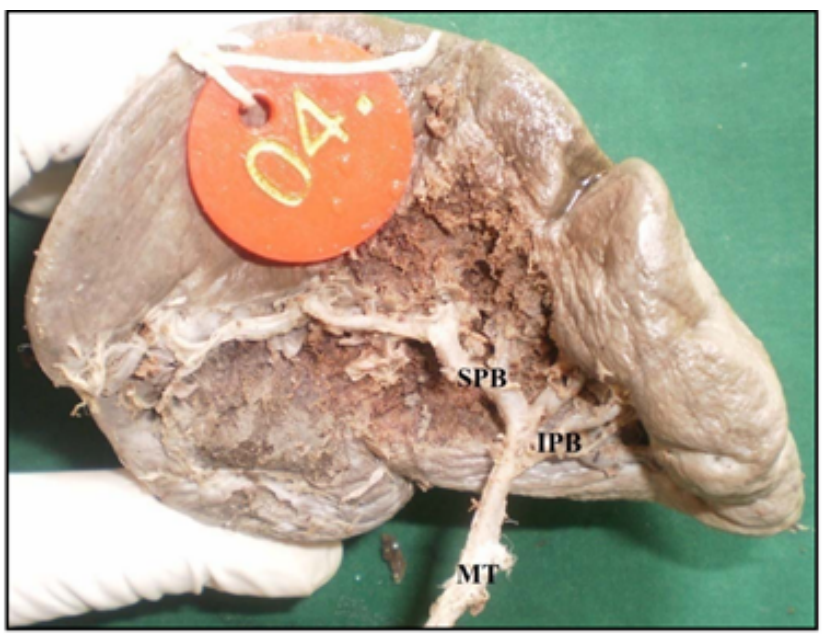

Fig. 5: Marginal type of branching pattern (MT - Main Trunk, SPB - Superior Primary Branch, IPB InferiorPrimary Branch)

In some spleens, a branch arising from splenic artery itself or one of its primary branch which does not pierce the hilum, but goes to the poles of spleen. These are known as superior and inferior polar arteries. These arteries also supply a particular segment of spleen, which can be considered as the polar segments. ${ }^{16}$ In our study we observed superior polar artery was present in 18(22.8\%) specimens and inferior polar artery was present in 32 $(40.5 \%)$ specimens and both superior and inferior polar artery was seen in $5(6.3 \%)$ specimens. The comparison between other studies is given in Table 4 .

Superior polar arteries arising from main trunk was present in $12(67 \%)$ specimens and superior polar arteries 
arising from primary branch were seen in $6(33 \%)$ specimens. Inferior polar artery was seen arising from main trunk in $15(47 \%)$ specimens, from left gastroepiploic artery in $9(28 \%)$ specimens and from primary branch in $8(25 \%)$ specimens.

Katrisis $\mathrm{E}$ et $\mathrm{al}^{5}$ in their study noted that, the polar arteries arise either from main trunk or primary branch. Silva LFA et $\mathrm{al}^{9}$ observed $16 \%$ arising from main trunk and $20 \%$ arising from terminal branches. Swamy VL et al ${ }^{11}$ noted all polar arteries arising from main trunk only.

The spleen is divided into segments; each segment is supplied by its own segmental branches. These segments are separated by a definite avascular plane. But rarely there may be an inter-segmental anastomosis. In the present study, anastomosis between the primary segmental branches seen in $11(13.9 \%)$ specimens. The comparison of anastomosis between segmental branches with previous studies is given in Table 5.

The inter-segmental anastomosis can be of three types.

1. Extra parenchymal Anastomosis.

2. Intra parenchymal anastomosis.

3. Sub capsular anastomosis.

In the present study we observed, the extra-parenchymal anastomosis of primary segmental branches were seen in $5(6.3 \%)$ specimens, the intra parenchymal anastomosis was seen in $3(3.7 \%)$ specimens and sub capsular type of anastomosis was seen in $3(3.7 \%)$ specimens. Comparison of type of anastomosis with the previous studies is given in Table 6.

Based on terminal branching pattern, the splenic artery pedicle can be classified into two types.

1. Distributive type where the splenic artery divides away from the hilum of the spleen with long terminal branches that enters through the hilum.

2. Marginal type where the artery divides at the hilum with short terminal branches.

In the present study we observed, the distributive type of branching pattern was present in 50(63.3\%) specimens and the marginal type of branching pattern was present in $29(36.7 \%)$ specimens.

A study conducted by Henschen et al. ${ }^{17}$ classified three types of pattern and observed, short distribution in $10 \%$, long distribution in $40 \%$ and marginal type in $46 \%$. The comparison of present study with previous studies is given in Table 7.

\section{Conclusion}

The spleen is a highly vascular and friable organ. It is the largest of secondary lymphoid organ, which contains $25 \%$ of the body's lymphoid tissue and has both haematological and immunological functions. Total splenectomy is commonly done after a splenic injury, which leads to decrease in the immunity and predisposes the normal host to overwhelming life threatening infections and also creates an altered haematological picture. To overcome this, partial splenectomy can be done by ligating a particular segmental branch of splenic artery.

The partial removal of the spleen is possible, as the spleen is divided into segments, separated by fibrous septa and each segment is supplied by its own main artery. The presence of splenic segmentation could be attributed to its development or to the terminal division of the artery. Better anatomical knowledge about segmental distribution of splenic artery and its variations are important for the partial removal of the organ.

\section{Source of Funding}

None.

\section{Conflicts of Interest}

None.

\section{References}

1. Standring S. The Anatomical Basis of Clinical Practice. In: Gray's Anatomy. Edinburg: Churchill Livingstone Elsevier; 2008. p. 1239_ 45 .

2. Kyber E. Uber die Milz des Menschen and einiger sangetiere. Arch Microsk Anat Entw Mech. 1870;6:540-70.

3. Gupta CD, Gupta SC, Arora AK, Jeya SP. Vascular segments in human spleen. J Anat. 1976;121(3):613-6.

4. Mikhail Y, Kamel R, Nawar NNY, Rafla MFM. Observations on the mode of termination and parenchymal distribution of the splenic artery with evidence of splenic lobation and segmentation. J Anat. 1979;128(2):253-8.

5. Katritsis E, Parashos A, Papadopoulos N. Arterial Segmentation of the Human Spleen by Post-Mortem Angiograms and Corrosion-Casts.

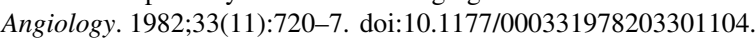

6. Mandarim LCA, Sampaio FJ, Passos MA. Vascular segmentation of the spleen in the new born infants. Anatomical support for partial resection. J Chir (Paris). 1983;120(8-9):471-3.

7. Garcia-Porrero JA, Lemes A. Arterial Segmentation and Subsegmentation in the Human Spleen. Cells Tissues Organs.

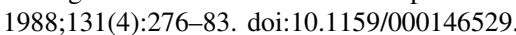

8. Sow ML, Dia A, Ouedraogo T. Anatomic basis for conservative surgery of the spleen. Surg Radiol Anat. 1991;13(2):81-7. dov:10.1007/bf01623878

9. Silva LFA. Morfometric study of arterial branching of the spleen compared to radiological study. Rev Col Bras Cir. 2011;38(3):181-

10. Chaware PN, Belsare SM, Kulkarni YR, Pandit SV, Ughade JM. Variational anatomy of the segmental branches of the splenic artery. JCDR. 2012;6(3):336-8.

11. Swamy VLI, Suseelamma D, Jadhav SD, Balbhim ZR, Mithil NP, Chaitanya K. Study of prehilar branches of splenic artery by dissection method. Int J Med Res Health Sci. 2013;2(3):620-3. d01:10.5958/].2319-5886.2.3.109.

12. Londhe SR. Study of vascular pattern in human spleen by carrion cast method. Al Ameen J Med Sci. 2013;6(2):167-9.

13. Holibkova A, Machalek L, Houserkova D, Ruzieka V. A contribution to the types of branching and anastomosis of the splenic artery in the human spleen. Biomedical Papers. 1998;141(1):49-52.

14. Michels NA. The variational anatomy of the spleen and splenic artery. Am J Anat. 1942;70(1):21-72. doi:10.1002/aja.1000700103. 
15. Brunicardi FC. Schwartz's Principles of Surgery. 8th ed. McGraw-Hill Companies Inc; 2005.

16. Redmond HP, Redmond JM, Rooney BP, Duignan JP, BouchierHayes DJ. Surgical anatomy of the human spleen. Br J Surg. 1989;76(2):198-201. doi:10.1002/b]S.1800760230.

17. Henschen C. Die chirurgischen Anatomie der Milzgefisse. Schweiz Med Wochenschr. 1928;58:161-70.

\section{Author biography}

Shwetha K, Tutor
Dakshayani K R, Professor and Head

Cite this article: Shwetha K, Dakshayani K R. Study on branching pattern of segmental branches of splenic artery in human cadaveric spleens by dissection method. Indian J Clin Anat Physiol 2021;8(1):30-35. 